Article

\title{
Speeds of Young E-Cyclists on Urban Streets and Related Risk Factors: An Observational Study in Israel
}

\author{
Victoria Gitelman ${ }^{1, *(\mathbb{D})}$, Anna Korchatov ${ }^{1}$ and Wafa Elias ${ }^{2}$ \\ 1 Transportation Research Institute, Technion-Israel Institute of Technology, Technion City, 3200003 Haifa, \\ Israel; grabarn@technion.ac.il \\ 2 Département of Civil Engineering, Shamoon College of Engineering, 84 Jabotinsky st., 84100 Ashdod, Israel; \\ wafael@sce.ac.il \\ * Correspondence: trivica@technion.ac.il
}

Received: 2 March 2020; Accepted: 12 June 2020; Published: 18 June 2020

\begin{abstract}
In Israel, a growing use of electric bicycles by youngsters has been noted, with an increase in related injuries. In this study, an observational survey was conducted on typical urban streets, aiming to characterize the riding speeds of young e-cyclists compared to regular cyclists and the associated risk factors in their behaviors. The survey covered 39 sites in eight cities, and included 1054 cyclists. The results showed that mean speeds of young e-cyclists were higher than those of regular cyclists at all types of sites, with a difference of $6-9 \mathrm{~km} / \mathrm{h}$. The mean speeds of e-bicycles were below $25 \mathrm{~km} / \mathrm{h}$, as prescribed by law, but the 85-percentile speeds were higher. E-cyclist speeds depend on the type of street, road layout and place of riding. More e-cyclists used the roadway compared to regular cyclists, however, on divided roads, more e-cyclists used sidewalks in spite of the law prohibition, thus endangering pedestrians. The majority of cyclists did not wear helmets. The unsafe behaviors of teenage e-cyclists increase the injury risk for themselves and for other road-users. Thus, separate bicycle infrastructure should be promoted in the cities. Road safety education and training of young e-cyclists with stronger enforcement of traffic regulations are also needed.
\end{abstract}

Keywords: e-bicycles; youngsters; speeds; behaviors; observation

\section{Introduction}

Electric power-assisted bicycles (also known as electric bicycles, e-bicycles or e-bikes) are fitted with an electric engine and a battery. The electric assistance to the rider reduces the physical efforts required for riding and thus increases the potential to expand the role of cycling in urban transportation. Indeed, in many countries there has been a sharp increase in the use of electric bicycles, constituting the largest and most rapid uptake of alternatively fueled vehicles in the history of motorization [1]. Worldwide sales of electric bicycles were estimated to be over 40 million units in 2015, of which 36.8 million (91.9\%) were sold in China and over 2.3 million (5.8\%) in Europe. In Europe, between the years 2011 and 2015, the total amount of e-bicycle sales increased by 88\%, with a particular increase in sales in Germany, the Netherlands, Austria, Switzerland, Italy and France [1,2]. Hurst and Gartner [3] presented a forecast scenario of the e-bike growth by world regions, and suggested that annual e-bike sales in the world (excluding China) will approach 4 million in 2020; an aggressive forecast suggests even higher numbers.

In Israel, a country with a population of about 9 million inhabitants and no long tradition of cycling, the amount of electric bicycles in use is growing rapidly. According to various estimates, over 200,000 e-bicycles were sold in a period of three years, 2013 to 2015 [4]. The Israeli Tax Department reported that electric bicycles present $16 \%$ of the total bicycle imports into the country; the transportation 
planning administration estimated that by the end of 2017, between 227 and 246 thousand electric bicycles were in use on Israeli roads [5].

In Europe, an e-bicycle must satisfy the conditions defined by EN 15194 [6]: the engine power is limited to 250 watts, the speed is up to $25 \mathrm{~km} / \mathrm{h}$ and pedaling is obligatory. E-bicycles that meet these requirements do not need a driving license, insurance and vehicle license, and can travel on bicycle lanes and roads, like a regular bicycle. A similar approach was adopted in Israel. According to the traffic regulations [7], permissions and prohibitions relating to standard e-bicycles are identical to those for conventional bicycles. In addition, in Israel, only people aged 16 and above are allowed to ride electric bicycles. Riding of e-bicycles is permitted on bicycle facilities and on roadways, and not allowed on sidewalks, crosswalks or other pedestrian places. In urban areas, wearing a helmet is mandatory for cyclists under the age of 18. A rider can carry another person on the bicycle only if it is fitted for carrying, i.e., has more than a single seat.

E-cycling can provide a convenient form of mobility in urban areas, being an attractive alternative to private cars. Studies showed that the durations and distances of trips performed by e-bike riders increased compared to trips on conventional bicycles, and that e-bicycles may replace private car travel for daily purposes [8-10]. Electric bicycles are useful for people who are unable to ride conventional bicycles due to physical limitations or ageing [11,12]. Due to the use of electrical power, e-bicycles are environmentally-friendly. For these reasons, e-cycling is associated with the expected benefits of improved accessibility, reduced traffic congestion, lower energy consumption and positive health effects $[9,10,13]$.

However, along with mobility benefits, there is a growing concern of e-cyclists' injuries, resulting from the increasing exposure and apparently higher speeds. Cycling injury was examined extensively by previous research, which showed the vulnerability of bicycle riders in mixed vehicle traffic e.g., [14,15]. The experience showed, e.g., [16], that a higher level of cycling safety can be achieved by promoting traffic calming measures, establishing separate cycling infrastructure, attaining greater awareness of cyclists' presence among vehicle drivers and lower cycling speeds. It is reasonable to assume that similar vulnerability concerns remain for e-cyclists (as unprotected road users), while a possibility for higher speeds and other differences in e-cyclist behaviors relative to conventional cyclists may increase the injury risk. For example, in China, evaluation studies of road traffic injury revealed a higher risk of e-bike riders being killed or suffering severe injuries in a road crash compared to conventional bicycle riders [8,17]. Evaluations in the Netherlands showed that the risk of e-cyclists being injured in a road crash is higher compared to conventional cyclists [18], after controlling for age, gender and amount of bicycle use. Research findings from Sweden and Germany indicated that the chance of e-bicycle riders being involved in conflicts with other road users is higher compared to conventional bicyclists, and that the risk of being involved in a conflict increases at intersections, in the proximity of crosswalks and with an increase in riding speeds $[19,20]$.

In Israel, data from the national trauma registry showed a dramatic 6-fold increase in the amount of patients hospitalized due to e-bike crashes, over the three-year period, 2013-2015 [21], which was clearly associated with the increased use of this transport means. More recent data showed that e-bicycle-related injury is still growing in the country. Based on police reports, it was estimated [5] that over the five-year period, 2014-2018, thirty-five people were killed in Israel in crashes involving e-cyclists and that the average annual increase in serious injuries in such crashes was about $55 \%$.

Besides the increasing exposure, the higher vulnerability of e-bicycle riders may be related to their behaviors. Empirical studies have shown that electric bicycle riders usually ride faster than conventional bicycle riders, though the speed differences are not always large. For example, in the naturalistic cycling studies conducted in Tennessee, USA, Germany and Sweden, the mean speeds of e-bicycles were higher by only $2-4 \mathrm{~km} / \mathrm{h}$ compared to regular bicycles $[19,22,23]$. At the same time, studies from China reported on the frequency of riding at unnecessarily high speeds, particularly near signalized intersections [24-26]. Injuries sustained from collisions at faster speeds were shown to be more serious than at slower speeds $[27,28]$. 
Studies from the USA and Europe demonstrated more safety-aware behaviors of electric bicycle users with regard to helmet use, compliance with traffic signs and more careful riding on bicycle-shared paths, or no considerable differences compared to conventional bicycle riders [11,22,29]. In contrast, studies from China found high rates of traffic violations and dangerous behaviors among e-bike riders, such as passing through red lights and carrying another person on the bike [30,31]. Schleinitz et al. [32] re-analyzed the data obtained in a naturalistic cycling study in Germany with regard to red-light running and found a relatively low violation rate $(16 \%)$ that was similar for e-bicycle and regular bicycle riders. The researchers highlighted the limited applicability of the Chinese findings to the Western context.

Studies conducted in other countries, e.g., in the USA, Australia and Europe, found that e-bicycle users are mainly men, aged thirty and above, with higher income and education levels compared to users of conventional bicycles $[9,29,33]$. In Israel, unlike other countries, a high share of riders on electric bicycles are young: teenagers below the age of 18 , some of them younger than 16 . In the cities, young e-bicycle riders can be encountered on sidewalks, roads, bicycle routes and junctions, especially in the hours of going to and coming from school, when some of them ride at seemingly high speeds and/or ignore traffic regulations. This phenomenon was frequently discussed in the media and by various authorities in Israel, whilst its actual characteristics were generally unknown since observational studies on the topic had not been conducted. The data from the national trauma registry in Israel (e.g., [21]) and from police reports (e.g., [5]) indicated that about a third of injuries in e-bicycle-related crashes were to children (below 18). However, the extent and the forms of risky behaviors among young e-cyclists were not studied in the past, thus making it difficult to develop remedial measures for reducing injury. In particular, it is important to identify whether young e-cyclists are prone to engaging in certain risky behaviors, in order to suggest legislation, enforcement or education measures to address them.

Being aware of the growing phenomenon of using e-bicycles by youngsters in Israeli towns, with their seemingly dangerous behaviors and the already negative implications on road traffic injury, a study of teen e-cyclists' behaviors was undertaken [34], which was based on field observations. The whole study was focused on young e-cyclists (teenagers), thus the observations were performed during the common hours of their commuting to and from school, and to other destinations during leisure hours. The initial surveys characterized the young e-cyclist behaviors at various urban locations, including intersections and street sections, and their interactions with other road users [34]. The initial surveys applied video-recordings and included over two hundred locations in fifteen cities. This paper presents a complementary survey conducted in the same study, which aimed to characterize the riding speeds of young e-cyclists on typical urban streets, their behavior patterns related to regular cyclists, and factors associated with selecting riding speeds.

The main incentive for the study was to explore real-life young e-cyclists' behaviors, since the international literature on the topic is not extensive, while most findings refer to adult e-cyclists. Moreover, in local conditions, teen e-cyclists represent a substantial share of e-bike-related injuries, which necessitates attention to this group of riders. In a more general context, cycling in general and e-cycling in particular are considered as an essential component of sustainable urban growth, e.g., [35]. However, creating conditions for safe e-cycling in urban areas, and fitting infrastructure solutions for the safe sharing of urban space among various road users, still presents a challenge. In this context, observational studies may be helpful for a better understanding of e-cyclist behaviors in various urban settings and hence for developing measures for safer integration of e-cycling in cities.

\section{Materials and Methods}

\subsection{Observational Sites}

In this study, an observational survey was performed to characterize the riding speeds of teen e-cyclists compared to regular teen cyclists, in Israeli cities, and additionally, to compare behavior 
patterns of both groups and to examine factors associated with speed selection by young e-riders. Ethical approval of the study was obtained from the Behavioral Sciences Research Ethics Committee of the Technion-Israel Institute of Technology (approval number 2020-014).

As mentioned above, the whole study [34] explored teen e-cyclists' behaviors, thus, the observational surveys were undertaken during the hours of pupils' trips to and from school and during leisure hours. The observational sites for the study were selected in the surroundings of high-schools (for ages 14-18) and in the vicinity of commercial/community centers and other possible attractions for teenagers, in the cities. Data on cycling exposure are not available in the country. Hence, the database of observational sites for the study was prepared in several steps, aiming to attain a wide coverage of typical urban locations in a representative mix of towns with higher presence of e-cyclists. The selection of cities for the study was based on the experience of previous local field surveys which indicated that large- and medium-sized towns situated along the seaside and in the center of the country, with flat landscapes and medium-to-high socio-economic levels, are associated with higher use of e-bicycles by youngsters. In such towns, larger numbers of young e-cyclists can be met. On this basis, a preliminary list of town candidates for the survey was drawn up, moving along the seaside from the north to the center of the country-the Tel-Aviv metropolitan area and its surroundings.

In order to select areas with a higher potential for e-bicycle use, in each city, a preliminary list of high-schools with large amounts of pupils-more than 800, was prepared (using an internet site with information on all high-schools in Israel), and maps with school surroundings were drafted. High-school sites were visited on weekday mornings. If a substantial amount of e-bicycles were parked near the gates, the study team consulted with the school guard regarding the main directions of young e-cyclists' travels to and from the school. The street grid of the school surroundings was examined and traffic settings of the streets were visually checked during the field surveys, classified and kept in the study database [34]. In a similar way, observation sites for afternoon leisure activities of young e-cyclists were selected, following preliminary field surveys in the vicinity of commercial centers and other attractions in city centers, and having checked that a certain number of young e-cyclists was observed. In total, the study database included 225 sites in 49 areas of fifteen cities; all the sites were used for video-recordings of young e-riders in the initial observational surveys [34].

Speed measurements of electric and regular bicycles were planned on typical urban streets. Since the speed survey was aimed at unobtrusive speeds of riders, speeds were measured on street sections only. Based on the study database [34] and the familiarity with common street settings in Israeli cities, for the speed survey, five types of urban streets were defined, such as: (1) undivided roads in city centers, (2) undivided roads in residential areas, (3) pedestrian zone streets, (4) divided roads in city centers, and (5) divided roads in residential areas. Furthermore, in selecting urban streets for speed observations, the preference was given to collector streets versus local ones since collector streets are characterized by higher vehicle traffic volumes and pedestrian activities and, typically, mixed land uses, and are frequently associated with road safety problems in urban areas of the country [36,37]. The presence of pedestrians and higher traffic volumes on the street increases the potential for conflicts between e-cyclists and other road users and thus such streets are more relevant for observational studies seeking to improve urban road safety.

The street sections selected for the survey were straight and plain and had common layout characteristics of urban infrastructure in Israel. Undivided roads have one traffic lane per direction and no median; divided roads have two travel lanes for vehicle traffic per direction and a raised median with greenery. Typical width of vehicle lanes is $3.25 \mathrm{~m}$, of sidewalks-at least $2.5 \mathrm{~m}$ in residential areas, $3.5 \mathrm{~m}$ in city centers; the width of a pedestrian zone starts from $5 \mathrm{~m}$; the width of a bicycle path, if available- $1.5 \mathrm{~m}$.

In total, the speed survey data were collected on 39 observational sites in eight cities, providing a substantial coverage of the study database [34]. The cities included: Nahariya, Hadera, Netanya, Kfar Saba, Kiryat Yam, Givatayim, Ramat Gan and Tel-Aviv. The survey sites presented a mix of large-, medium- and small-sized towns (two, three and three, respectively), which are situated in the north 
and in the center of the country (three and five, respectively). Thus, the composition of the survey sites was sufficiently diverse to reflect the areas of teen e-cycling in the country. The subdivision of observational sites according to the pre-defined types of urban streets was as follows: 7 sites on undivided roads in city centers, 8 - on undivided roads in residential areas, 7-on pedestrian streets, 9-on divided roads in city centers, 8 - on divided roads in residential areas.

\subsection{Data Collection}

Speeds were measured for teenager cyclists only (up to the age of 18); adult cyclists were excluded from the survey. The measurements were performed using a speed gun, which is a common tool for speed surveys in urban areas [38]. Since speed gun values are sensitive to the angle of measurement $[38,39]$, the measurement should be as close as possible to zero angle relative to the moving subject. The survey was conducted on working days, during hours of higher appearance of the studied population, i.e., before 8 am in the morning and between 12-14 in the afternoon near the high-schools' areas, and between 15-18 in city centers. Speeds were measured in the middle of street sections, under natural riding conditions and good weather conditions (warm and dry); cases with disturbance to natural riding, e.g., transport of a big package, accompanying a walking pedestrian, etc., or with disturbance to road traffic (construction site, crash, etc.) were not included in the data. No police enforcement was present during the data collection (in general, police enforcement is not common on urban streets in Israel). To attain a uniform data collection, the time-frame of the survey was defined as follows: at each site, the observer was instructed to stay for an hour and to measure speeds of about 30 cyclists, of which at least 15 should be e-cyclists and at least 10-regular cyclists. Each subject that appeared on the spot, in the time-frame, and satisfied the definition, was described in the data collection form. The survey design was in line with the approach that is common in national observational surveys of traffic behaviors [38], when small samples of observations are collected on a wide number of sites, and the sites reflect a mix of geographic distribution and various social-economic levels of the studied population. This approach enables the attainment of average estimates in accordance with the pre-defined types of sites (i.e., five street types, in our case).

Age groups of riders were decided on a visual basis. The identification of teen cyclists in the speed survey was based on the experience of substantial analyses of video-records of teen e-cyclists in the first stage of the whole study [34]. In total, over 2000 video-films were examined in the study, of which two thirds were from the areas near high-schools. For consistency in recognition, sets of typical examples were developed for use by the study team and calibration training was conducted for the observers to recognize the age.

For each teen cyclist, beside the travel speed, additional information was collected: type of bicycle (electric or regular); gender; age group (below or over 16); wearing a helmet (yes or no); riders' composition, i.e., cycling alone or in a group; place of riding-roadway (vehicle lanes), bus lane, sidewalk or bicycle path; carrying a passenger (yes or no). In addition, the length of each street segment was indicated as a possible factor that may influence the riding speeds (less than $100 \mathrm{~m}$, 100-200 m, 200-300 m, 300-400 m or 400-500 m). A distinction between the two age subgroups of teens was applied in the survey, since, in May 2016, a law change was introduced that restricted the use of e-bicycles to the age of 16 and above. As a result, e-riding below the age of 16 became illegal but actual e-bike use by younger teens was not necessarily discontinued, and the survey was supposed to examine this feature as well.

A pilot was conducted in December 2016 and the main speed survey was carried out in February-March 2017. All data collection was performed by the same team member; the pilot was supervised by a senior researcher. The data were coded in the speed survey database.

\subsection{Data Analyses}

Statistical analyses were carried out on the survey database to characterize the riding speeds of electric and regular bicycles, at various types of urban sites, to consider behavior patterns of young 
cyclists at various locations, and to examine factors associated with the selecting of higher or lower speeds by e-cyclists. The analyses included several components, as follows:

- First, speed indicators were estimated for each type of site, for regular and electric bicycles. A comparative analysis of mean speeds between various street types and between the electric and regular bicycles was performed. To examine the significance of differences between the speed indicators, the ANOVA test with Tukey post-hoc analysis was applied (the difference is significant with $p<0.05)$.

- Second, a comparative analysis of young cyclists' characteristics and behaviors between e-cyclists and regular cyclists was conducted, across various types of sites. The indicators were estimated as a percentage of certain features out of the total sample of riders observed. To examine the significance of differences between various characteristics among the two types of cyclists, a Pearson chi-square test was applied.

- Third, a multivariate analysis was conducted to identify factors influencing e-cyclist speeds. For this, a multivariate linear regression model [40] was fitted to the riding speeds of e-cyclists, when variables such as site type, cyclist's gender and age group, riders' composition, wearing a helmet, carrying a passenger and the length of the street section, were examined among potential explanatory variables for speeds. The model goodness-of-fit was measured by a percentage of the explained variance and by the Fisher test.

Furthermore, a number of assumptions need to be fulfilled for applying a linear regression model such as [41]: a linear relationship between the dependent variable and the predictors, a constant variance within the error term (no heteroscedasticity), absence of multi-collinearity within the predictors, and the residuals should be normally distributed. The assumptions were checked on the study database.

\section{Results}

\subsection{Riding Speeds at Various Types of Sites}

In the speed survey, data on a total sample of 1054 young bicycle riders were collected, including 203 riders on undivided roads in city centers, 230 - on undivided roads in residential areas, 180 - on pedestrian streets, 218-on divided roads in city centers, 223-on divided roads in residential areas. In total, the sample included 738 electric and 316 regular bicycle riders.

Table 1 and Figure 1 present the estimated indicators of riding speeds of electric and regular bicycles at various types of sites. It can be seen that the mean speeds of electric bicycles are consistently higher than those of regular bicycles, at all types of sites, with a difference in the range of $6-9 \mathrm{~km} / \mathrm{h}$.

Table 1. Riding speeds of electric and regular bicycles, at various types of sites.

\begin{tabular}{cccc}
\hline Type of Urban Site & Type of Bicycle & $\mathbf{N}$ & Mean Speed (Sd), km/h \\
\hline \multirow{2}{*}{ Undivided roads in city centers } & Regular & 60 & $11.9(4.1)$ \\
& Electric & 143 & $20.8(5.8)$ \\
\hline \multirow{2}{*}{ Undivided roads in residential areas } & Regular & 73 & $12.3(4.5)$ \\
& Electric & 157 & $21.1(6.0)$ \\
\hline \multirow{2}{*}{ Pedestrian zone streets } & Regular & 58 & $10.8(4.0)$ \\
& Electric & 122 & $16.8(5.7)$ \\
\hline \multirow{2}{*}{ Divided roads in city centers } & Regular & 64 & $11.6(4.5)$ \\
& Electric & 154 & $20.2(6.3)$ \\
\hline \multirow{2}{*}{ Divided roads in residential areas } & Regular & 61 & $11.9(4.1)$ \\
& Electric & 162 & $21.3(6.0)$ \\
\hline
\end{tabular}




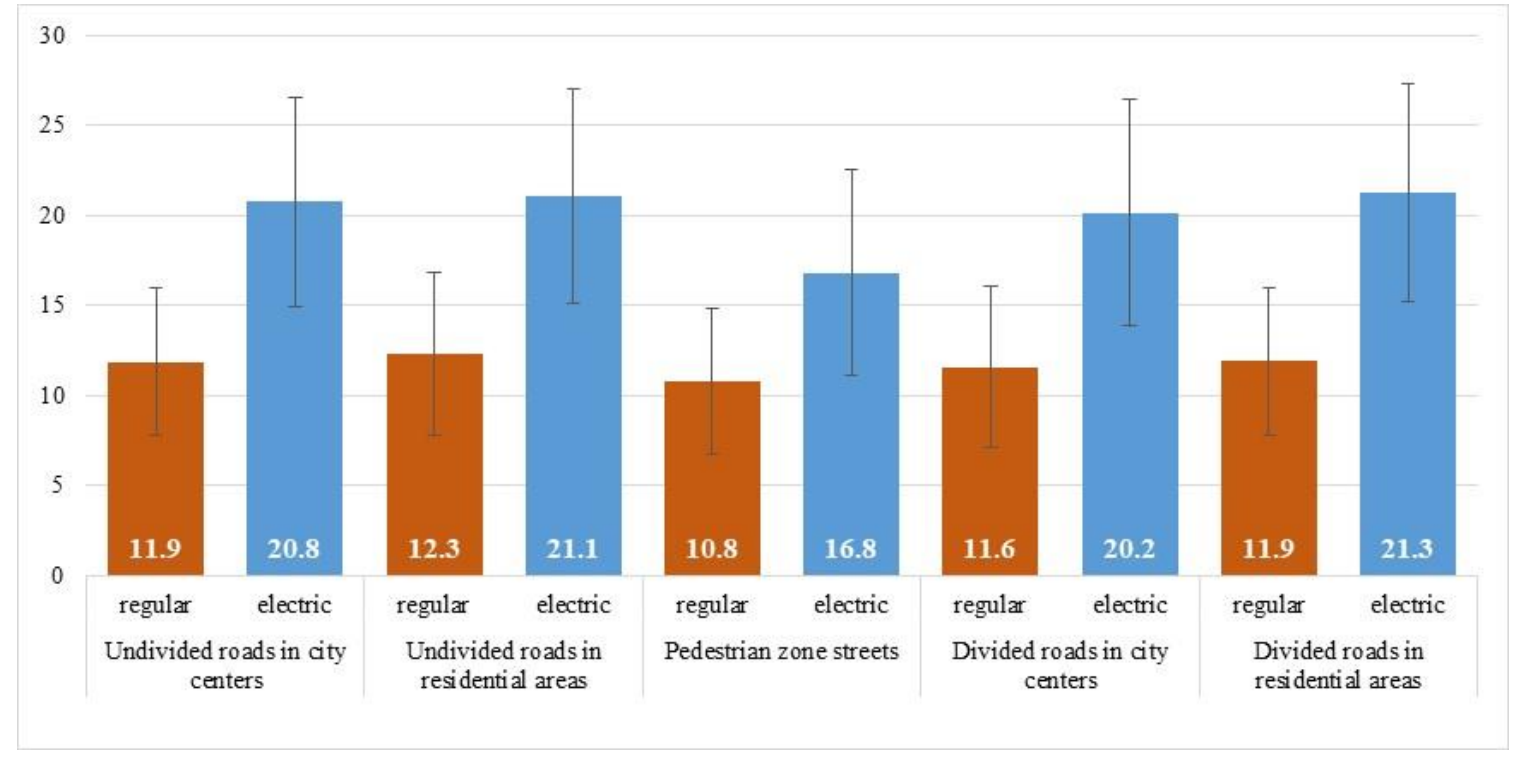

Figure 1. Mean riding speeds, $\mathrm{km} / \mathrm{h}$ ( \pm a standard deviation) of electric and regular bicycles, at various types of sites.

The mean speeds of electric bicycles were around $20-21 \mathrm{~km} / \mathrm{h}$ on various types of street sections with a mixed use by pedestrians and vehicles, whereas, on streets with pedestrian zones, their speeds were lower-a mean speed of about $17 \mathrm{~km} / \mathrm{h}$. At all types of sites, the mean speeds of electric bicycles were below $25 \mathrm{~km} / \mathrm{h}$, the limit prescribed by law for e-bicycles. However, a wide range of values of riding speeds was observed, where the mean speeds plus standard deviations were about $27 \mathrm{~km} / \mathrm{h}$, on all types of street sections with mixed traffic, and $23 \mathrm{~km} / \mathrm{h}$ in pedestrian zones. This implies that the riding speeds of a considerable number of electric bicycles are sufficiently high to present a danger for pedestrians, when sidewalks are used for riding. The mean speeds of regular bicycles were around $11-12 \mathrm{~km} / \mathrm{h}$ at all types of sites. With an addition of one standard deviation, speed values of $15-17 \mathrm{~km} / \mathrm{h}$ are attained. Evidently, travel speeds of regular bicycles were less hazardous for pedestrians.

According to the ANOVA test with Tukey post hoc analysis, the mean speeds of electric bicycles differed significantly from the speeds of regular bicycles $(\mathrm{F}=63.91, p<0.0001)$. Pair-comparisons of the mean speeds indicated a significant difference $(p<0.05)$ between the two groups of cyclists, at each type of site. Furthermore, in the comparisons of speeds for regular bicycles, no significant difference was found between different types of sites. As for e-bicycles, significant differences in speed values were found for pedestrian streets compared to all other street types; among the other street types no significant difference was found.

\subsection{Characteristics and Behaviors of E-Cyclists and Regular Cyclists, at Various Types of Sites}

Table 2 presents the results of comparisons between the characteristics and behaviors in the samples of electric and regular bicycle riders, at different types of sites. The results show that in general, the majority of riders at various types of sites were boys (75-89\% on electric bicycles, $77-92 \%$ on regular bicycles). With regard to gender, among all types of sites, a close to significant difference $(p<0.10)$ was found for divided roads in city centers, where a higher share of girls was observed on regular bicycles compared to electric bicycles: $20 \%$ vs. $11 \%$, respectively. 
Table 2. Characteristics and behaviors in the samples of electric vs. regular bicycle riders, at various types of sites (percent of riders observed).

\begin{tabular}{|c|c|c|c|c|c|c|c|c|c|c|c|}
\hline \multirow[t]{2}{*}{ Characteristics/Behaviors } & \multirow[t]{2}{*}{ Values } & \multicolumn{2}{|c|}{$\begin{array}{c}\text { Undivided Roads in City } \\
\text { Centers }\end{array}$} & \multicolumn{2}{|c|}{$\begin{array}{c}\text { Undivided Roads in } \\
\text { Residential Areas }\end{array}$} & \multicolumn{2}{|c|}{ Pedestrian Streets } & \multicolumn{2}{|c|}{$\begin{array}{c}\text { Divided Roads in City } \\
\text { Centers }\end{array}$} & \multicolumn{2}{|c|}{$\begin{array}{l}\text { Divided Roads in } \\
\text { Residential Areas }\end{array}$} \\
\hline & & RB & EB & RB & EB & RB & EB & RB & EB & RB & EB \\
\hline \multirow{3}{*}{ Cyclist gender } & Girls & 23 & 15 & 19 & 18 & 16 & 25 & 20 & 11 & 8 & 15 \\
\hline & Boys & 77 & 85 & 81 & 82 & 84 & 75 & 80 & 89 & 92 & 85 \\
\hline & $x^{2}$ & \multicolumn{2}{|c|}{2.22} & \multicolumn{2}{|c|}{0.06} & \multicolumn{2}{|c|}{1.91} & \multicolumn{2}{|c|}{$3.28 *$} & \multicolumn{2}{|c|}{1.99} \\
\hline \multirow{3}{*}{ Cyclist age group } & $>16$ & 53 & 65 & 45 & 61 & 79 & 77 & 67 & 64 & 46 & 44 \\
\hline & $<16$ & 47 & 35 & 55 & 39 & 21 & 23 & 33 & 36 & 54 & 56 \\
\hline & $x^{2}$ & \multicolumn{2}{|c|}{2.45} & \multicolumn{2}{|c|}{$5.14 * *$} & \multicolumn{2}{|c|}{0.12} & \multicolumn{2}{|c|}{0.25} & \multicolumn{2}{|c|}{0.04} \\
\hline \multirow{3}{*}{ Wears a helmet } & No & 95 & 98 & 96 & 98 & 98 & 98 & 98 & 99 & 100 & 99 \\
\hline & Yes & 5 & 2 & 4 & 2 & \multirow{2}{*}{\multicolumn{2}{|c|}{0.10}} & \multirow{2}{*}{\multicolumn{2}{|c|}{0.02}} & \multirow{2}{*}{\multicolumn{2}{|c|}{0.38}} \\
\hline & $x^{2}$ & \multicolumn{2}{|c|}{1.24} & \multicolumn{2}{|c|}{0.94} & & & & & & \\
\hline \multirow{3}{*}{ Rides alone } & No & 10 & 7 & 11 & 13 & 14 & 18 & 3 & 6 & 13 & 14 \\
\hline & Yes & 90 & 93 & 89 & 87 & 86 & 82 & 97 & 94 & 87 & 86 \\
\hline & $x^{2}$ & \multicolumn{2}{|c|}{0.53} & \multicolumn{2}{|c|}{0.15} & \multicolumn{2}{|c|}{0.51} & \multicolumn{2}{|c|}{0.70} & \multicolumn{2}{|c|}{0.01} \\
\hline \multirow{3}{*}{ Place of riding } & Roadway incl. bus lane & 57 & 81 & 60 & 88 & 0 & 0 & 38 & 52 & 48 & 64 \\
\hline & Sidewalk or bicycle path & 43 & 19 & 40 & 12 & 100 & 100 & 63 & 48 & 52 & 36 \\
\hline & $x^{2}$ & & & & & & & & & & \\
\hline & No & 100 & 99 & 100 & 94 & 100 & 99 & 100 & 98 & 100 & 98 \\
\hline Carries a passenger & Yes & 0 & 1 & 0 & 6 & 0 & 1 & 0 & 2 & 0 & 2 \\
\hline & $x^{2}$ & & & & & & & & & & \\
\hline & $<200$ & 48 & 54 & 79 & 83 & 74 & 78 & 55 & 62 & 34 & 29 \\
\hline Street section length, $\mathrm{m}$ & $200-500$ & 52 & 46 & 21 & 17 & 26 & 22 & 45 & 38 & 66 & 71 \\
\hline & $x^{2}$ & & & & & & & & & & \\
\hline
\end{tabular}

Notes: RB—regular bicycles, EB—electric bicycles. Significant difference with ${ }^{*} p<0.1,{ }^{* *} p<0.05,{ }^{* * *} p<0.01$ 
The majority of e-cyclists were over the age of 16 at most sites, except for divided roads in residential areas (61-77\% vs. $44 \%$, respectively). On regular bicycles, teenagers over the age of 16 were the majority on pedestrian streets and on divided roads in city centers; in other sites they were about a half (45-53\%) of the total cyclists observed. For this metric, a significant difference was found for undivided roads in residential areas: there the share of regular cyclists over 16 was much lower than the share for e-cyclists: $45 \%$ vs. $61 \%(p<0.05)$.

The vast majority of cyclists of both types: $98-99 \%$ of e-cyclists, $95-100 \%$ of regular cyclists, did not wear a helmet, in spite of the legal requirement in the country. In this sense, no difference in behaviors of the two types of cyclists was found across various types of sites.

At all types of sites, most cyclists rode alone: $82-94 \%$ of e-cyclists, and $86-97 \%$ of regular cyclists. Riding in a group was observed more frequently on pedestrian streets and on undivided roads: in $14-18 \%$ and in $11-14 \%$ of cases, respectively, but without a significant difference between cyclist types.

None of the regular cyclists observed carried a passenger, while a few e-cyclists did. The highest proportion of teenager e-cyclists who carried passengers was observed on undivided roads in residential areas $(6 \%)$, where a significant difference between the two types of riders was indicated.

The main difference between the two groups of cyclists was found with regard to selecting the place of riding, at various types of sites. Figure 2 illustrates the distributions of place of riding, by site type and bicycle type. On pedestrian streets, obviously, all cyclists were observed on pedestrian facilities (or bicycle paths when available). On all other street types, more e-cyclists were consistently observed on the roadway compared to regular cyclists. On undivided streets, $81-88 \%$ of e-cyclists preferred the roadway (or bus lane) compared to $57-60 \%$ of regular cyclists; on divided roads, the similar proportions were $52-64 \%$ for e-cyclists and $38-48 \%$ for regular cyclists. The differences in selecting the place of riding were significant between the two groups of cyclists at all street types, except for pedestrian streets (significant differences were found both in the detailed and aggregated comparisons—see $p$-values below Figure 2 and Table 2).

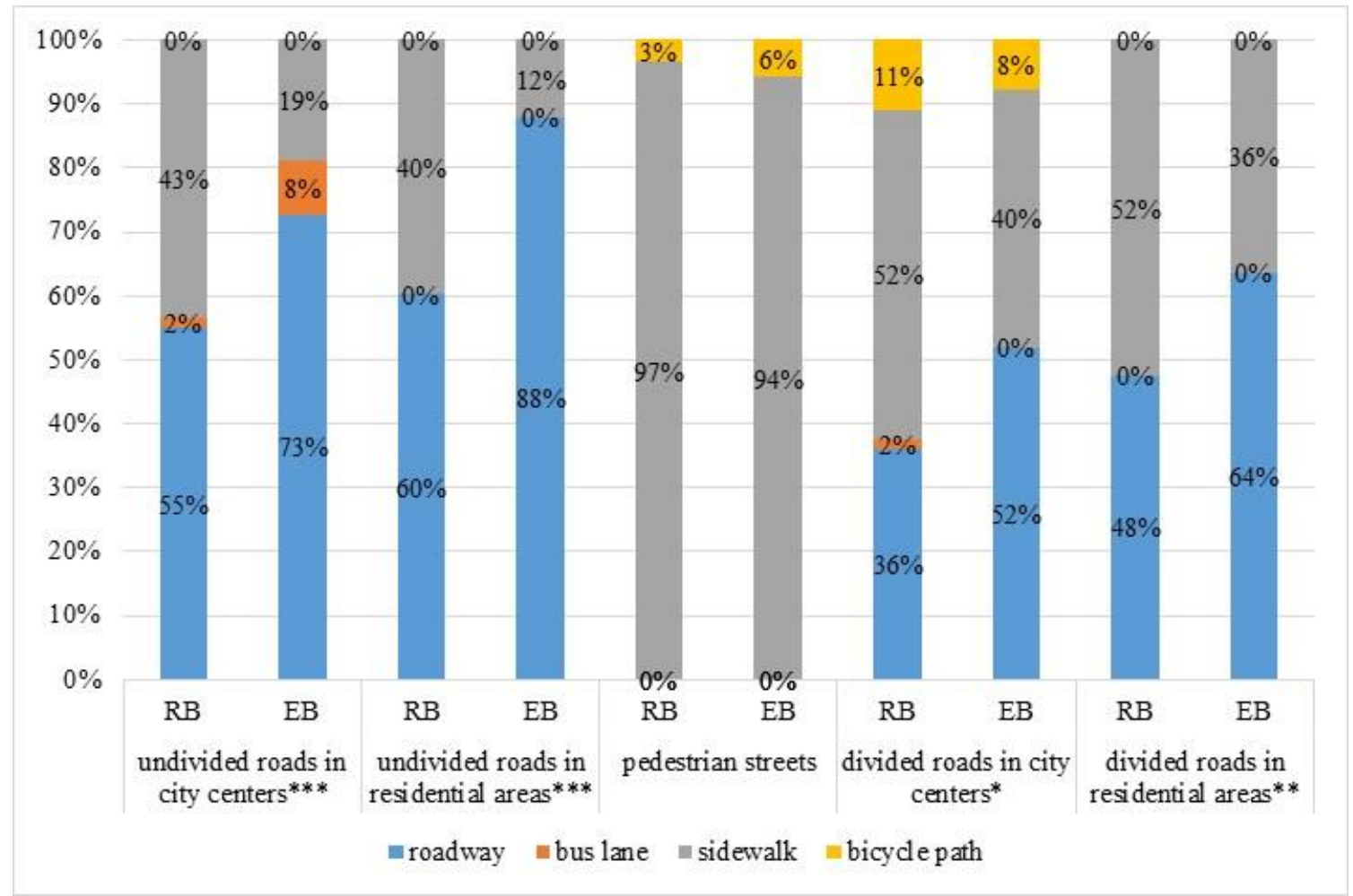

Figure 2. Distributions of place of riding, by site type and bicycle type. RB-regular bicycles, EB-electric bicycles. Significant difference with ${ }^{*} p<0.1,{ }^{* *} p<0.05,{ }^{* * *} p<0.01$. 
It can be noted that on divided roads and, particularly, on divided roads in city centers, with apparently higher vehicle and pedestrian traffic, more cyclists used pedestrian facilities (or bicycle paths when available). Such a preference reduces the risk of cyclist injury in mixed vehicle traffic but increases the risk of possible pedestrian injury on sidewalks (and is illegal).

In addition, the lengths of street sections were found to be similar in the samples of both cyclist types (see Table 2) and, hence, this characteristic did not serve as a confounder for the estimated speed values.

\subsection{Factors Associated with Speed Selection by E-Cyclists}

Using the database of e-cyclists collected in the speed survey, an explanatory model was adjusted to the e-cyclist speeds, when the characteristics of cyclists and sites were examined as potential explanatory variables. Table 3 shows the model fitted to e-cyclist speeds.

Table 3. Explanatory model fitted to e-cyclist speeds.

\begin{tabular}{|c|c|c|c|c|}
\hline Variables & Estimate & Std. Error & $t$-Value & $\operatorname{Pr}(>|t|)$ \\
\hline (Intercept) & 21.442 & 1.045 & 20.514 & $<0.0001^{* * *}$ \\
\hline Site type: undivided roads in residential areas vs. \# & 1.052 & 0.692 & 1.521 & 0.1287 \\
\hline Site type: pedestrian streets vs. $\#$ & -0.431 & 0.832 & -0.518 & 0.6045 \\
\hline Site type: divided roads in city centers vs. ${ }^{\#}$ & 1.129 & 0.715 & 1.579 & 0.1148 \\
\hline Site type: divided roads in residential areas vs. $\#$ & 1.945 & 0.712 & 2.732 & $0.0064^{* *}$ \\
\hline Gender: boys vs. girls & 0.540 & 0.563 & 0.959 & 0.3380 \\
\hline Age group: $<16$ years old vs. $>16$ years old & -1.526 & 0.444 & -3.434 & $0.0006^{* * *}$ \\
\hline Wearing helmet: yes vs. no & -0.495 & 1.635 & -0.303 & 0.7623 \\
\hline Riding alone vs. in group & 1.096 & 0.662 & 1.655 & $0.0984 *$ \\
\hline Place of riding: bus lane vs. roadway & 2.790 & 1.759 & 1.586 & 0.1131 \\
\hline Place of riding: sidewalk vs. roadway & -4.238 & 0.537 & -7.896 & $<0.0001^{* * *}$ \\
\hline Place of riding: bicycle path vs. roadway & 1.105 & 1.420 & 0.778 & 0.4367 \\
\hline Carrying passenger: yes vs. no & -4.584 & 1.291 & -3.55 & $0.0004^{* * *}$ \\
\hline Length of street section: $100-200 \mathrm{~m}$ vs. $<100$ & -1.812 & 0.654 & -2.77 & $0.0058^{* *}$ \\
\hline Length of street section: $200-300 \mathrm{~m}$ vs. $<100$ & -2.123 & 0.723 & -2.943 & $0.0034^{* *}$ \\
\hline Length of street section: $300-400 \mathrm{~m}$ vs. $<100$ & -0.016 & 0.869 & -0.018 & 0.9854 \\
\hline Length of street section: $400-500 \mathrm{~m}$ vs. $<100$ & 0.597 & 1.437 & 0.415 & 0.6781 \\
\hline
\end{tabular}

Several statistical assumptions that needed to be fulfilled for linear regression analysis were examined for the fitted model [41,42]. A diagnostic plot of residuals versus fitted values (Figure A1a, Appendix A) showed no distinct patterns; this indicates that a linear relationship between the predictors and the outcome variable can be assumed. A scale-location plot (Figure A1b) was used to check the homogeneity of variance of the residuals (homoscedasticity) along the ranges of predictors. In general, a horizontal line with equally spread points can be seen, yet, the variances of the residual points slightly decreased with the higher value of the fitted outcome variable. A non-constant variance score test was insignificant $(p=0.162)$, suggesting that the data are homoscedastic. Multi-collinearity among predictors was checked using a correlation matrix. The strongest correlation value was 0.38 , indicating a weak correlation between the potential explanatory variables. A normal Q-Q plot (Figure A1c) was used to examine whether the residuals are normally distributed; all the points fell approximately along this reference line, thus supporting the normality assumption. In addition, the Shapiro-Wilk normality test showed that the residuals are normally distributed $(p=0.752)$.

The model showed that e-cyclist gender and wearing a helmet did not have a significant influence on the speed level, yet there is a tendency toward higher speeds for boys versus girls and a tendency toward lower speeds for those wearing a helmet. According to the Type III tests, the impacts of other characteristics were significant: with $p<0.05$ for the site type; $p<0.01$ for the length of street section; $p<0.001$ for the age group, place of riding and carrying a passenger; $p<0.1$ for riding alone versus riding in a group. The model indicated that: 
- On divided roads in residential areas, divided roads in city centers and undivided roads in residential areas, speeds were higher than on undivided roads in city centers (as a base category), by $1.94,1.13$ and $1.05 \mathrm{~km} / \mathrm{h}$, respectively. On the other hand, speeds on pedestrian streets were slightly lower, by $0.4 \mathrm{~km} / \mathrm{h}$ (yet, the differences were not statistically significant for most site types, except for divided roads in residential areas).

- The speed was lower for younger cyclists, below 16, compared to those over 16 , by $1.5 \mathrm{~km} / \mathrm{h}$.

- Riding alone versus in a group of cyclists increased the speed by $1.1 \mathrm{~km} / \mathrm{h}$.

- The speed on sidewalks was lower, by $4.2 \mathrm{~km} / \mathrm{h}$, than the speed on the roadway (as a base category). In addition, riding on a bus lane or on a bicycle path was associated with an increase in riding speed related to the base category, by 2.8 and $1.1 \mathrm{~km} / \mathrm{h}$, respectively, but these differences were not statistically significant.

- Carrying a passenger was associated with a lower speed, by $4.6 \mathrm{~km} / \mathrm{h}$.

- The speeds on the relatively short street sections (of 100-200 $\mathrm{m}$ and 200-300 $\mathrm{m}$ in length) were lower, by $1.8-2.1 \mathrm{~km} / \mathrm{h}$, than speeds on the shortest sections (less than $100 \mathrm{~m}$, as a base category). On longer segments, of 300-400 $\mathrm{m}$ and $400-500 \mathrm{~m}$ in length, speeds were similar and higher than for the base category (but the differences are not significant). It is possible that on the medium-length street sections, where lower speeds were observed, more disturbances to the smooth cycling were present compared to the longer street sections.

It should be noted that the model showed the impacts of various characteristics on e-cyclist speeds, while controlling for the other variables considered. In general, the findings indicate that e-cyclist speeds are higher on divided roads (both in city centers and in residential areas) and on undivided roads in residential areas, for riders over the age of 16 , for single riders and on longer street sections. Conversely, e-cyclist speeds are lower on undivided roads in city centers and on pedestrian streets, for younger riders (below 16), for those who ride in groups or carry a passenger, and for riding on sidewalks or on shorter street sections.

\section{Discussion}

Being aware of the growing use of e-bicycles by youngsters in Israel and the reported increase in traffic injuries [5,21], the observational survey of teen cyclists was undertaken in this study to explore the riding speeds of young e-cyclists, on typical urban streets. The study results indicated that the mean speeds of young e-bicyclists, in Israeli towns, were around $20-21 \mathrm{~km} / \mathrm{h}$ on urban streets with vehicle and pedestrian traffic, and lower-about $17 \mathrm{~km} / \mathrm{h}-$ on streets with pedestrian zones. These values are in the range of mean riding speeds reported by German studies of e-bicycles [20,23] but are higher than the average speeds reported in the USA [22] and in Sweden [43]. The higher values received in this study compared to the latter cases may be related to the measurement conditions, e.g., examining university campus streets in [22] versus common urban streets in the current study; estimating average riding speeds through the city in [43] versus point speed measurements in this study. In general, the range of e-cyclist speeds observed in this study, with maximum values of $34-35 \mathrm{~km} / \mathrm{h}$, was close to the ranges reported by previous studies, with maximum values of $31-33 \mathrm{~km} / \mathrm{h}[20,22,23]$. Hence, the level of young e-cyclists' speeds in Israel may be judged as common and not exceptional in relation to the comparable findings abroad.

The mean speeds of electric bicycles, in this study, were consistently higher than those of regular bicycles, at all types of sites, with a difference in the range of $6-9 \mathrm{~km} / \mathrm{h}$. This result was expected due to the electric power-assistance of e-bicycles, which stimulates their higher attractiveness for urban travel [8-10]. However, the differences in the mean riding speeds between the two groups of cyclists were higher in the current study compared to previous findings $[19,22,23]$, where gaps of $2-4 \mathrm{~km} / \mathrm{h}$ were reported. This distinction may be related to the population examined in the current study-teenagers-whereas other studies were of adults. Teenagers generally are physically unable to 
reach the same speeds as adults when riding regular bicycles, which in turn increases the speed gap between the e-cyclists and regular cyclists.

At all types of sites, the mean speeds of electric bicycles were below $25 \mathrm{~km} / \mathrm{h}$, the limit prescribed by the traffic law [7] for e-bicycles. However, the 85-percentile speeds of e-cyclists (the mean speeds plus standard deviations) were about $27 \mathrm{~km} / \mathrm{h}$ on all streets with mixed vehicle and pedestrian traffic, indicating that riding speeds of a considerable number of young e-cyclists exceed the law limit. The observed speeds were sufficiently high to present a danger for walking pedestrians (when sidewalks are used for riding). The police reports indicated [5] that $9 \%$ of injuries in e-bicycle crashes in Israel have been pedestrians and that the number of pedestrian injuries in such crashes, in recent years, has been increasing annually by $55 \%$. Thus, a separation in urban infrastructure is required to enable safe walking and cycling on urban streets. In addition, riding at high speeds is dangerous for e-bicyclists themselves, since injuries sustained from collisions at higher speeds were shown to be more serious than at lower speeds $[27,28]$.

The study model indicated that e-cyclist speeds are higher for teens over the age of 16 and for single riders. Conversely, e-cyclist speeds are lower for younger riders (below 16), and for those who ride in groups or carry a passenger. A tendency to higher speeds for boys versus girls was indicated, yet, the difference was not statistically significant. These findings cannot be directly compared with previous research on e-cycling, from other countries, since those studies considered adult cyclists. However, the findings are in line with previous research on young road user behaviors, which consistently indicated that, with the increase in age, adolescents, and particularly, males, are more likely to exhibit risk-taking behaviors, for example, as pedestrians $[44,45]$. Since both in this study and in the previous observations in Israel [34], the majority of young e-cyclists observed were boys and over the age of 16, a tendency to ride at higher speeds appears to be common for a substantial share of teen e-cyclists in the country.

The vast majority of young e-cyclists observed in this study (98-99\%) did not wear a helmet, in spite of the national law requiring doing so [7]. This unsafe behavior was common for various types of sites. In larger observational surveys of teen e-cyclists across various locations in the cities [34], the findings were generally similar as, on average, only $8 \%$ of riders wore a helmet. Research has shown that injuries to the head or neck are prevalent among e-bicycle riders [21,46], hence wearing a helmet will provide safety benefits for e-cyclists.

In addition, a small share of e-cyclists (1-6\%, at various sites) carried a passenger, in spite of the law prohibiting this. According to the Israeli traffic law [7], e-riders should be over the age of 16, yet a substantial share of e-cyclists observed in this study were below 16, particularly in residential areas. The high extent of violations of the age restriction that was observed in this study can be related to the fact that the update to the law that raised the age of e-cycling to 16 was introduced in Israel only in mid-2016, while the observations took place just half a year later.

Disregarding the regulation on obligatory helmet wearing for children below 18 and other traffic laws, generally, reflects the lack of police enforcement and publicity campaigns on the topic. Recently, public authorities in Israel have begun to pay more attention to the issue of e-cycling safety [5] but the impacts of policy changes need to be evaluated in the future.

Another worrying finding of this study concerns the place of riding. According to the traffic law [7], e-bicycles are allowed to ride on bicycle facilities and on roadways, and are not allowed to ride on sidewalks and other pedestrian facilities. The study results demonstrated that, indeed, more e-cyclists were consistently observed on the roadways compared to regular cyclists. However, on various street types, non-negligible shares of young e-cyclists were observed on sidewalks, thus violating the law and endangering pedestrians. The extent of use of pedestrian facilities by young e-cyclists was higher on divided roads, particularly in city centers, which are characterized by high vehicle volumes, apparently reflecting the riders' intention to reduce the risk of cycling in mixed vehicle traffic (when bicycle paths are not available).

The study model showed that e-cycling speeds on sidewalks were lower, by $4 \mathrm{~km} / \mathrm{h}$ on average, than the speeds on the roadway and that, in general, e-cyclists moved slower on pedestrian streets 
than on other street types. This may indicate that e-cyclists are aware of pedestrian presence and adopt their speeds, respectively. However, e-cycling speeds were sufficiently high to present a risk of possible pedestrian injury on sidewalks (and this danger is already reflected in actual e-bike crash statistics, e.g., [5]).

The study findings showed that e-cyclist speeds are higher on divided roads, both in city centers and in residential areas, and on undivided roads in residential areas, and are lower on undivided roads in city centers and on pedestrian streets; the speeds were also lower on shorter street sections. This indicates that young e-cyclists may change their behaviors according to the urban environment, road and traffic conditions.

Traffic regulations [7] instruct e-bicycles to use regular bicycle infrastructure when available. Indeed, in the current study, some e-cyclists were observed on bicycle paths, when those were present (6-8\%, on two street types). However, bicycle lanes and paths are not common yet in most Israeli towns, while, in general, the construction of bicycle-related infrastructure in urban areas is still in its initial stage. Thus, to promote the safe use of e-bicycles in Israeli cities, the main focus should be on a wider application of common bicycle infrastructure, in accordance with design guidelines. Better separation between the sidewalks, roadways and bicycle paths, at various types of urban settings e.g., [47], will reduce the problem of speed differences and conflicts in the interaction between various road users. Separate cycling infrastructure was proven to be effective in improving cycling safety [16].

The results presented in this study should be taken with caution and treated as preliminary observations, because the study design could not rely on exposure data of young e-cyclists in the country and a direct comparison of the study results to other countries was not possible, due to a lack of findings, from other countries, on young e-cyclist behaviors. In future, a case-control study design would be required to enhance the value of the data collected in field observations. In the current study, a case-control design was not realizable due to the time and funding constraints.

Additional study limitations lie in its observational character, which might impact, for example, on the judgment of the age of cyclists. The study focus was restricted to the commuting behaviors of teen e-cyclists, on weekdays only. Further research with larger data samples and more details on traffic, road and urban environment conditions may contribute to a better knowledge on selecting riding speeds by e-cyclists. Comparisons of riding speeds and behaviors across various age groups, e.g., teenagers versus adults, would be useful as well. Road user behaviors may vary by day of week, e.g., on weekends versus weekdays, and by the period of day, e.g., at nighttime versus daytime. They can also be influenced by changes in traffic volumes, police enforcement, weather conditions, etc. More observational studies would be helpful to understand the impacts of various environmental conditions on e-cycling behaviors. More research is needed to explore the impacts of various infrastructure solutions on a safer integration of e-cycling into the urban space.

\section{Conclusions}

The study showed that young e-cyclist speeds mostly depend on the urban environment-the type of street, road layout and place of riding. The speeds of young e-cyclists in Israeli towns are not exceptional compared to e-cycling speeds reported abroad, but they are sufficiently high to present a danger for pedestrians, when walking and cycling infrastructure are not separated.

Young e-cyclists in Israel are prone to engage in risky behaviors such as not wearing helmets, using pedestrian facilities for riding, and carrying a passenger without a special seat; these are also violations of the traffic rules. Thus, publicity, road safety education and training of young e-cyclists, and the support of stronger police enforcement of traffic regulations, are needed in order to reduce such behaviors.

E-cycling can serve as an essential component of sustainable urban growth, in general [35], and can promote active travel habits among young people, in particular. However, its integration is deterred by an absence of appropriate infrastructure for safe e-cycling in urban areas. Wider application of infrastructure solutions for the safe sharing of urban space among e-cyclists, regular cyclists and 
pedestrians, in conjunction with road safety education and enforcement, will promote safer speeds and behaviors among young e-cyclists.

Author Contributions: Conceptualization, V.G. and W.E.; methodology, V.G.; software, A.K.; validation, A.K.; formal analysis, V.G. and A.K.; investigation, V.G. and A.K.; writing-original draft preparation, V.G.; writing-review and editing, V.G. and W.E.; visualization, A.K. and V.G.; project administration, V.G. and W.E.; funding acquisition, W.E. All authors have read and agreed to the published version of the manuscript.

Funding: This research was funded by the Ministry of Science, Technology and Space, Israel, grant number 3-12476.

Acknowledgments: This research was supported by the Ministry of Science, Technology and Space, Israel. The authors want to thank Eng. Robert Carmel and Eng. Michael Saeed, for collecting data for this study.

Conflicts of Interest: The authors declare no conflict of interest.

\section{Appendix A}

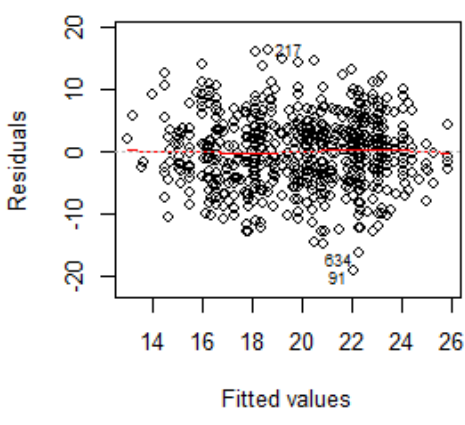

(a). Residuals vs. Fitted

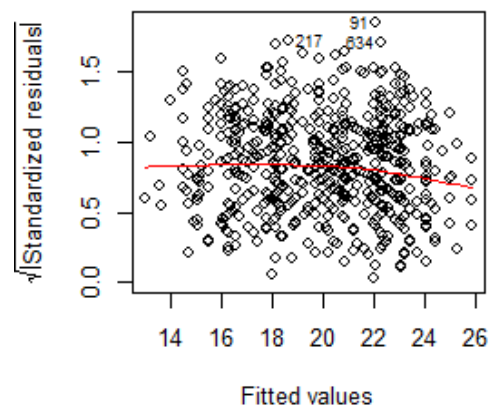

(b). Scale-location

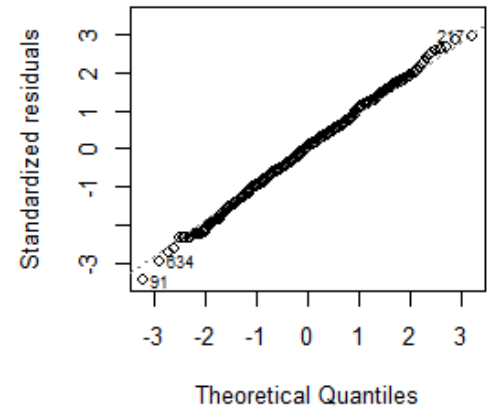

(c). Normal Q-Q

Figure A1. Diagnostic plots of the linear regression model.

\section{References}

1. Fishman, E.; Cherry, C. E-bikes in the mainstream: Reviewing a Decade of Research. Transp. Rev. 2016, 36, 72-91. [CrossRef]

2. Dozza, M.; Werneke, J.; Mackenzie, M. E-BikeSAFE: A naturalistic cycling study to understand how electrical bicycles change cycling behaviour and influence safety. In Proceedings of the International Cycling Safety Conference 2013, Helmond, The Netherlands, 20-21 November 2013.

3. Hurst, D.; Gartner, J. Electric Bicycles Global Market Opportunities, Barriers, Technology Issues, and Demand Forecasts for E-Bicycles, Pedal-Assist Bicycles And E-Bicycle Batteries and Motors; Navigant Consulting, Inc.: Chicago, IL, USA, 2013; Available online: http://www.navigantresearch.com (accessed on 5 March 2017).

4. Morgenstein, D. Electric Bikes-A Transportation Disaster or an Urban Solution? Status-Journal of Managerial and Strategic Thinking. 13 June 2016. Available online: www.status.co.il (accessed on 5 December 2017).

5. Shachak, M. Bicycles, Electric Bicycles and Electric Scooters: Data on Accidents, Injuries, Regulations and Inspection. Center of Research and Information, the Knesset. 2018. Available online: https://knesset.gov.il/ mmm (accessed on 20 November 2019).

6. European Norms EN 15194. Cycles. Electrically Power Assisted Cycles. EPAC Bicycles; European Committee for Standardization: Brussels, Belgium, 2009.

7. Traffic Regulations. 2016. Available online: https://www.nevo.co.il.law_htm/Law01 (accessed on 20 November 2017).

8. Cherry, C.; Cervero, R. Use Characteristics and mode choice behavior of electric bike users in China. Transp. Policy 2007, 14, 247-257. [CrossRef]

9. Johnson, M.; Rose, G. Electric bikes-cycling in the new world city: An investigation of Australian electric bicycle owners and the decision making process for purchase. In Proceedings of the Australasian Transport Research Forum 2013, Brisbane, Australia, 2-4 October 2013; Available online: http://www.patrec.org/atrf.aspx (accessed on 20 November 2017). 
10. Fyhri, A.; Fearnley, N. Effects of e-bikes on bicycle use and mode share. Transp. Res. Part D Transp. Environ. 2015, 36, 45-52. [CrossRef]

11. MacArthur, J.; Dill, J.; Person, M. E-Bikes in the North America: Results from an online survey. Transp. Res. Rec. J. Transp. Res. Board 2014, 2468, 123-130. [CrossRef]

12. Boele-Vos, M.J.; Commandeur, J.J.F.; Twisk, D.A.M. Effect of physical effort on mental workload of cyclists in real traffic in relation to age and use of pedelecs. Accid. Anal. Prev. 2017, 105, 84-94. [CrossRef]

13. Rose, G. E-bikes and urban transportation: Emerging issues and unresolved questions. Transportation 2012, 39, 81-96. [CrossRef]

14. Wegman, F.; Zhang, F.; Dijkstra, A. How to make more cycling good for road safety? Accid. Anal. Prev. 2012, 44, 19-29. [CrossRef]

15. OECD/ITF, 2013. Cycling, Health and Safety; OECD International Transport Forum Publishing/ITF: Paris, France, 2013. [CrossRef]

16. Schepers, P.; Twisk, D.; Fishman, E.; Fyhri, A.; Jensen, A. The Dutch road to a high level of cycling safety. Saf. Sci. 2017, 92, 264-273. [CrossRef]

17. Hu, F.; Lv, D.; Zhu, J.; Fang, J. Related risk factors for injury severity of e-bike and bicycle crashes in Hefei. Traffic Inj Prev. 2014, 15, 319-323. [CrossRef]

18. Schepers, J.P.; Fishman, E.; Den Hertog, P.; Klein Wolt, K.; Schwab, A.L. The safety of electrically assisted bicycles compared to classic bicycles. Accid. Anal. Prev. 2014, 73, 174-180. [CrossRef]

19. Dozza, M.; Piccinini, G.F.B.; Werneke, J. Using naturalistic data to assess e-cyclist behavior. Transp. Res. Part F 2016, 41, 217-226. [CrossRef]

20. Petzoldt, T.; Schleinitz, K.; Heilmann, S.; Gehlert, T. Traffic conflicts and their contextual factors when riding conventional vs electric bicycles. Transp. Res. Part F 2017, 46, 477-490. [CrossRef]

21. Siman-Tov, M.; Radomislensky, I.; Israel Trauma Group; Peleg, K. The casualties from electric bike and motorized scooter road accidents. Traffic Inj. Prev. 2017, 18, 318-323. [CrossRef]

22. Langford, B.C.; Chen, J.; Cherry, C.R. Risky riding: Naturalistic methods comparing safety behavior from conventional bicycle riders and electric bike riders. Accid. Anal. Prev. 2015, 82, 220-226. [CrossRef]

23. Schleinitz, K.; Petzoldt, T.; Franke-Bartholdt, L.; Krems, J.; Gehlert, T. The German Naturalistic Cycling Study-Comparing cycling speed of riders of different e-bikes and conventional bicycles. Saf. Sci. 2017, 92, 290-297. [CrossRef]

24. Bai, L.; Liu, P.; Guo, Y.; Yu, H. Comparative analysis of risky behaviours of electric bicycles at signalised intersections. Traffic Inj. Prev. 2015, 16, 424-428. [CrossRef]

25. Wang, C.; Xu, C.; Xia, J.; Qian, Z. The effects of safety knowledge and psychological factors on self-reported risky behaviours including group violations for e-bike riders in China. Transp. Res. Part F Traffic Psychol. Behav. 2018, 56, 344-353. [CrossRef]

26. Yang, H.; Liu, X.; Su, F.; Cherry, C.; Liu, Y.; Li, Y. Predicting e-bike users' intention to run the red light: An application and extension of the theory of planned behaviour. Transp. Res. Part F Traffic Psychol. Behav. 2018, 58, 282-291. [CrossRef]

27. Li, X.; Yun, Z.; Li, X.; Wang, Y.; Yang, T.; Zheng, L.; Qian, J. Orthopedic injury in electric bicycle-related collisions. Traffic Inj. Prev. 2017, 18, 437-440. [CrossRef]

28. Siman-Tov, M.; Radomislenskya, I.; Peleg, K. A look at electric bike casualties: Do they differ from the mechanical bicycle? J. Transp. Health 2018, 11, 176-182. [CrossRef]

29. Scaramuzza, G.; Uhr, A.; Neimann, S. E-Bikes im Strassenverkehr-Sicherheitsanalyse. Bfu-Report nr. 72; Beratungsstelle fur Unfallverhutung: Bern, Switzerland, 2015.

30. Du, W.; Yang, J.; Powis, B.; Zheng, X.; Ozanne-Smith, J.; Bilston, L.; Wu, M. Understanding on-road practices of electric bike riders: An observational study in a developed city of China. Accid. Anal. Prev. 2013, 59, 319-326. [CrossRef] [PubMed]

31. Yang, X.; Huan, M.; Abdel-Aty, M.; Pemg, Y.; Gao, Z. A hazard-based duration model for analyzing crossing behavior of cyclists and electric bike riders at signalized intersections. Accid. Anal. Prev. 2015, 74, 33-41. [CrossRef] [PubMed]

32. Schleinitz, K.; Petzoldt, T.; Kroling, S.; Gehlert, T.; Mach, S. (E-)Cyclists running the red light-The influence of bicycle type and infrastructure characteristics on red light violations. Accid. Anal. Prev. 2019, 122, 99-107. [CrossRef] [PubMed] 
33. Popovich, N.; Gordon, E.; Shao, Z.; Xing, Y.; Wang, Y.; Handy, S. Experiences of electric bicycle users in the Sacramento, California area. Travel Behav. Soc. 2014, 1, 37-44. [CrossRef]

34. Gitelman, V.; Korchatov, A.; Carmel, R.; Elias, W. Young e-cyclists in Israeli cities: A characterization of typical behaviours and risk factors based on field observations. Trans. Transp. Sci. 2018, 9, 18-32. [CrossRef]

35. Adminaité-Fodor, D.; Jost, G. Safer Roads, Safer Cities: How to Improve Urban Road Safety in the EU. PIN Flash Report 37; European Transport Safety Council: Brussels, Belgium, 2019.

36. Gitelman, V.; Balasha, D.; Carmel, R.; Hendel, L.; Pesahov, F. Characterization of pedestrian accidents and an examination of infrastructure measures to improve pedestrian safety in Israel. Accid. Anal. Prev. 2012, 44, 63-73. [CrossRef] [PubMed]

37. Omer, I.; Gitelman, V.; Rofe, Y.; Lerman, Y.; Kaplan, N.; Doveh, E. Evaluating Crash Risk in Urban Areas Based on Vehicle and Pedestrian Modeling. Geogr. Anal. 2017, 49, 387-408. [CrossRef]

38. Hakkert, A.S.; Gitelman, V. Road Safety Performance Indicators: Manual; Deliverable D3.8 of the EU FP6 Project SafetyNet; SWOV Institute for Road Safety Research: Haag, The Netherlands, 2007.

39. Praticò, F.G.; Giunta, M. Quantifying the effect of present, past and oncoming alignment on the operating speeds of a two-lane rural road. Balt. J. Road Bridge Eng. 2012, 7, 181-190. [CrossRef]

40. Cohen, J.; Cohen, P.; West, S.G.; Aiken, L.S. Applied Multiple Regression/Correlation Analysis for the Behavioral Sciences; Routledge: New York, NY, USA, 2013.

41. Osborne, J.W.; Waters, E. Four assumptions of multiple regression that researchers should always test. Pract. Assess. Res. Eval. 2002, 8, 2.

42. Fox, J. The car Package. Companion Appl. Regres. 2001, 1, 4.

43. Dozza, M.; Werneke, J. Introducing naturalistic cycling data: What factors influence bicyclists' safety in the real world? Transp. Res. Part F 2014, 24, 83-91. [CrossRef]

44. Granié, M.A. Effects of gender, sex-stereotype conformity, age and internalization on risk-taking among adolescent pedestrians. Saf. Sci. 2009, 47, 1277-1283. [CrossRef]

45. Schwebel, D.C.; Davis, A.L.; O'Neal, E.E. Child pedestrian injury: A review of behavioral risks and preventive strategies. Am. J. Lifestyle Med. 2012, 6, 292-302. [CrossRef] [PubMed]

46. Papoutsi, S.; Martinolli, L.; Braun, C.B.; Exadaktylos, A.K. E-Bike Injuries: Experience from an Urban Emergency Department-A Retrospective Study from Switzerland. Emerg. Med. Int. 2014, 2014, 1-5. [CrossRef]

47. MassDOT. Separated Bike Lane Planning \& Design Guide; Massachusetts Department of Transportation: Boston, MA, USA, 2015. Available online: https://www.massdot.state.ma.us/highway/DoingBusinessWithUs/ ManualsPublicationsForms/SeparatedBikeLanePlanningDesignGuide.aspx (accessed on 20 February 2018). 